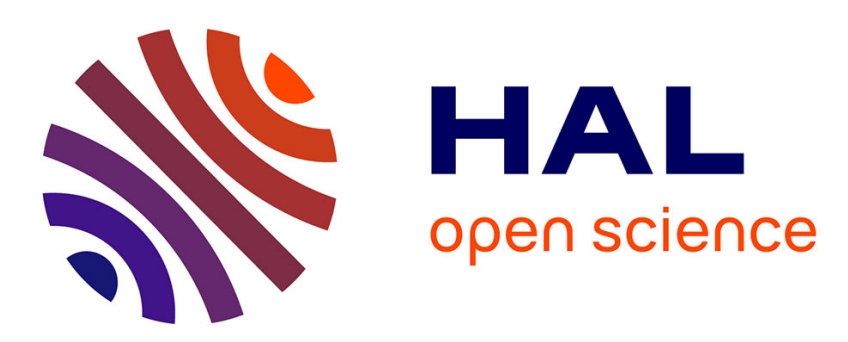

\title{
Activity inhibition and crystal polymorphism induced by active-site metal swapping
}

Elsie Yekwa, Joelle Khourieh, Bruno Canard, Nicolas Papageorgiou, Francois

Ferron

\section{- To cite this version:}

Elsie Yekwa, Joelle Khourieh, Bruno Canard, Nicolas Papageorgiou, Francois Ferron. Activity inhibition and crystal polymorphism induced by active-site metal swapping. Acta crystallographica Section D : Structural biology [1993-..], 2017, 73 (8), pp.641-649. 10.1107/S205979831700866X . hal03078421

\section{HAL Id: hal-03078421 \\ https://hal-amu.archives-ouvertes.fr/hal-03078421}

Submitted on 16 Dec 2020

HAL is a multi-disciplinary open access archive for the deposit and dissemination of scientific research documents, whether they are published or not. The documents may come from teaching and research institutions in France or abroad, or from public or private research centers.
L'archive ouverte pluridisciplinaire HAL, est destinée au dépôt et à la diffusion de documents scientifiques de niveau recherche, publiés ou non, émanant des établissements d'enseignement et de recherche français ou étrangers, des laboratoires publics ou privés. 


\title{
Activity inhibition and crystal polymorphism induced by active-site metal swapping
}

\author{
Elsie Yekwa $^{1,2}$, Joelle Khourieh ${ }^{1,2}$, Bruno Canard ${ }^{1,2}$, Nicolas Papageorgiou ${ }^{1,2}$, \\ François Ferron ${ }^{1,2^{*}}$
}

1 CNRS, AFMB UMR 7257, 13288, Marseille, France

2 Aix-Marseille Université, AFMB UMR 7257, 13288, Marseille, France

${ }^{*}$ Corresponding author : francois.ferron@afmb.univ-mrs.fr

\begin{abstract}
The Arenaviridae family is one of the two RNA viral families encoding a $3^{\prime}-5^{\prime}$ exonuclease in their genome. An exonuclease domain is carried by the Arenaviridae Nucleoprotein and targets dsRNA specifically. This domain is directly involved in suppression of innate immunity in the host cell. Like most phosphate-processing enzymes, it requires a divalent metal ion such as $\mathrm{Mg}^{2+}\left(\right.$ or $\mathrm{Mn}^{2+}$ ) as a cofactor to catalyse nucleotide cleavage and transfer reactions. On the other hand, Calcium $\left(\mathrm{Ca}^{2+}\right)$ inhibits this enzymatic activity, in spite of the fact that $\mathrm{Mg}^{2+}$ and $\mathrm{Ca}^{2+}$ are presenting comparable binding affinities and biological availability. Here, we study the molecular and structural effect of the calcium replacing the magnesium and its inhibition mechanism for phosphodiester cleavage, an essential reaction in the viral process of innate immunity suppression. We present for the first time the biochemical data and two high resolution structures of Mopeia virus exonuclease domain complexed with each ion respectively. We outline the consequences of the ion swap on the protein's stability, the catalytic site, and the functional role of a specific metal ion to enable the catalytic cleavage of a dsRNA substrate.
\end{abstract}

Keywords: - viral exonuclease ; Mopeia virus ; crystal polymorphism ; ion swap ; bfactor ; calcium inhibition ; exonuclease activity.

\section{Introduction}

The Arenaviridae is a family that comprises several human pathogens ; namely Machupo, Guanarito, Junin, Sabia, and Chapare viruses in South America, and Lassa and Lujo viruses in Africa ; responsible for causing haemorrhagic fevers. In west Africa, Lassa virus is responsible for several thousands of deaths every year while its eastern counter part, Mopeia virus, is non pathogenic and is therefore a good model to understand the biology of this viral 
family. Arenaviridae are enveloped single-stranded RNA viruses that share with the Coronaviridae the rare characteristic of encoding a 3'-5' exonuclease. The 3'-5' exonuclease domain is carried by the Nucleoprotein (NP), whose primary function is to package the viral genomic RNA (vRNA). The catalytic processing of dsRNA is critical to the viral life-cycle, as it is responsible for counteracting the type I interferon (IFN-I) cell defence. The exonuclease domain of Arenaviridae belongs to the DEDDh family of nuclease enzymes. It is specifically active on dsRNA substrates (Hastie et al., 2011). This acidic structural motif is responsible for chelating at least one $\mathrm{Mg}^{2+}$ in the enzymatic pocket. This "DEDD" motif is responsible for a catalytic reaction driven by a two-metal ion catalysis (TMIC) to form : 1) a stable intermediate, and then 2) break the $\mathrm{P}-\mathrm{O}$ bonds along the backbone of the nucleic acid chain (Palermo et al., 2015). Indeed, as shown by Steitz et al. (Steitz \& Steitz, 1993) and more specifically in arenavirus (Jiang et al., 2013), the TMIC reaction is driven by two divalent metal ions positioned on each side of the targeted phosphate bond to be cleaved (site $\mathrm{A}$ and $\mathrm{B}$ ). The metal ions facilitate an $\mathrm{S}_{\mathrm{N}}$ 2-type reaction, in which one metal ion favours the formation of the nucleophilic oxygen from a water molecule and the other helps the exit of the leaving group by associating with a no longer bridging phosphoryl oxygen. In the case of Arenaviridae exonuclease, the site A ion is filled in presence of the dsRNA substrate only (Jiang et al., 2013).

$\mathrm{Ca}^{2+}$ and $\mathrm{Mg}^{2+}$ are divalent metal ions involved in many biological processes. Despite their similar ionic properties, a number of enzymes are specific for $\mathrm{Mg}^{2+}$ ions. Arenaviridae exonuclease domains are to be added to the long list of enzymes acting on phosphates, activated in the presence of Magnesium ions $\left(\mathrm{Mg}^{2+}\right)$ and inhibited in the presence of calcium $\left(\mathrm{Ca}^{2+}\right)$ (Beaugé \& Campos, 1983; Colvin et al., 1991; Fukushima \& Post, 1978; Irimia et al., 2006; Junop \& Haniford, 1996; Knauf et al., 1974; Lu et al., 2013; Peeraer et al., 2004; Pingoud et al., 2009; Rosta et al., 2014; SKOU, 1957; Vipond et al., 1995). To address the question of why calcium inhibits the Arenaviridae exonuclease reaction, we studied the effect of calcium onto the activity, stability and structure of the exonuclease domain of Mopeia virus. We present and analyse two high resolution structures of the Mopeia virus exonuclease (NP-exo), domain complexed either with $\left(\mathrm{Mg}^{2+}\right)$ or $\left(\mathrm{Ca}^{2+}\right)$. Our data present clear evidences that the ripples of an ion swap goes beyond the inhibition of the catalytic reaction, impacting the thermal stability of the protein as well as the surface electrostatic potential which promotes crystal polymorphism. 


\section{Materials and methods}

\subsection{Protein production and purification}

cDNA corresponding to NP-exo (residues 365-570 - P19239) was cloned by recombination (Gateway, invitrogen) into pETG20A expression vector, which adds a cleavable N-terminal thioredoxin-hexahistidine tag. Protein was overexpressed in E.coli strain $\mathrm{C} 2566$ (NEB) grown in LB medium (AthenaES) over night at $17^{\circ} \mathrm{C}$ in presence of $100 \mu \mathrm{M}$ of $\mathrm{ZnCl}_{2}$. Bacteria were pelleted, frozen, and stored at $-80^{\circ} \mathrm{C}$. The exonuclease was purified by metal affinity chromatography using $2 \mathrm{ml}$ of His pur ${ }^{\mathrm{TM}}$ cobalt column (Thermo Scientific) (20 $\mathrm{mM}$ HEPES $\mathrm{pH}$ 7.5, $300 \mathrm{mM} \mathrm{NaCl}, 5 \mathrm{mM}$ imidazole, $5 \%$ glycerol and eluted with the same buffer with $250 \mathrm{mM}$ Imidazole). The tag was removed by cleavage with TEV protease followed by purification on a second cobalt affinity chromatography. Proteins were treated with $2 \mathrm{mM}$ EDTA in order to chelate any metal ion that would have been picked up during expression. Proteins were further purified by gel filtration using a superdex 75 column (GE Healthcare) in $20 \mathrm{mM}$ HEPES pH 7.5, $300 \mathrm{mM} \mathrm{NaCl}, 2 \mathrm{mM} \mathrm{MgCl}_{2}$ and $5 \%$ glycerol or in 20 mM HEPES pH 7.5, $300 \mathrm{mM} \mathrm{NaCl}, 2 \mathrm{mM} \mathrm{CaCl}_{2}$ and $5 \%$ glycerol. The catalytic mutant (D390A) of the exonuclease domain (Hastie et al., 2011) was generated by introducing a single point mutation using the Quick change site-directed mutagenesis kit (Stratagene); and expressed and purified following the established protocol.

\subsection{Exonuclease activity assay}

Reactions were carried out in a buffer containing $20 \mathrm{mM}$ Tris-Hcl pH $8,5 \mathrm{mM} \mathrm{MgCl} \mathrm{Mg}_{2}$ and $5 \mathrm{mM}$ DTT. The concentration of $\mathrm{MgCl}_{2}$ used was chosen after testing increasing concentrations ranging from $0.5 \mathrm{mM}$ to $15 \mathrm{mM}$ (data not shown). Standard reactions contained $0.25 \mu \mathrm{M}$ of protein (NP-exo or NP-exo mutant) and $1.25 \mu \mathrm{M}$ of radiolabeled $\mathrm{H} 4$ dsRNA substrate (Bouvet et al., 2010). After incubation at $37^{\circ} \mathrm{C}$, the reactions were quenched at intervals between 0 and 60 minutes by the addition of an equal volume of loading buffer (formamide containing $10 \mathrm{mM}$ EDTA). The products were heated at $70^{\circ} \mathrm{C}$ for 5 minutes, rapidly cooled on ice for 3 minutes followed by separation in a $20 \%$ polyacrylamide gel containing $8 \mathrm{M}$ urea and buffered with $0.5 \mathrm{X}$ Tris-borate-EDTA. Gels were exposed overnight to a phosphor screen and then visualized with a phosphoimager FLA-3000 (Fuji).

\subsection{Thermal shift assay}

A real-time PCR set up (Bio-rad) was used to monitor the thermal unfolding of the NP-exo in the absence of catalytic ion or in the presence of $\mathrm{Mg}^{2+}$ or $\mathrm{Ca}^{2+}$ ions. Proteins were equilibrated in a buffer containing $20 \mathrm{mM}$ HEPES pH 7.5, $300 \mathrm{mM} \mathrm{NaCl}, 5 \%$ glycerol. All 
reactions were set up in a final volume of $25 \mu 1$ in a 96-well plate with a total protein concentration of $1.8 \mathrm{mg} / \mathrm{ml}, 1 \mathrm{x}$ SYPRO Orange and incubated with or without $5 \mathrm{mM}$ of metal ions. The PCR plates were sealed with optical sealing tape (Bio-rad) and incubated in the PCR machine for 2 minutes at $20^{\circ} \mathrm{C}$ followed by $0.2^{\circ} \mathrm{C}$ increments to a final temperature of $95^{\circ} \mathrm{C}$. Thermal denaturation was monitored using SYPRO Orange (Life Technologies) and the fluorescence intensities were measured at $490 \mathrm{~nm}$ excitation and $530 \mathrm{~nm}$ emission wavelengths. The unfolding of proteins was monitored by following the increase in fluorescence of the probe as it binds to exposed hydrophobic regions of the denatured protein. The Tm was then calculated as the mid-log of the transition phase of the florescence curve using the Boltzmann equation. All measurements were performed in triplicate.

\subsection{Crystallization, and Structural determination of NP-exo}

Protein prepared in presence of $\mathrm{MgCl}_{2}$ or $\mathrm{CaCl}_{2}$ (see above) was concentrated to 12.5 $\mathrm{mg} / \mathrm{ml}$. NP-exo complexed with $\mathrm{Mg}^{2+}$ crystallized in $0.4 \mu \mathrm{l}$ drops containing $150 \mu \mathrm{l}$ of reservoir solution (0.1 M MES pH 6.5 and $25 \%(\mathrm{M} / \mathrm{W})$ PEG 8000) at $20^{\circ} \mathrm{C}$ using a sitting drop method. The crystals were protected by cryo-protectant that contained $20 \%$ glycerol in the crystallization solution and flash-frozen in liquid nitrogen.

Crystals of NP-exo complexed with $\mathrm{Ca}^{2+}$ were obtained using the same crystallization reservoir conditions. Diffraction data from several small crystals of the NP-exo complexed with $\mathrm{Mg}^{2+}$ were collected at the ESRF (Grenoble, France) on ID30-2 beam line while data from NP-exo complexed with $\mathrm{Ca}^{2+}$ were collected from a single crystal on ID23-2 beam line.

Data sets were processed using the program XDS (Kabsch, 2010). NP-exo complexed with $\mathrm{Mg}^{2+}$ data sets were merged and scaled with XSCALE (Kabsch, 2010) and truncated to 1.94 $\AA$ resolution due to sever anisotropy within the high resolution shell (1.9-1.7 $\AA$ ), resulting in an abnormal increase of the Rmerge statistics. The structure was solved using the Lassa virus exonuclease as search model (PDB 3Q7B). The search model was prepared by removing all ligands, metal ion and water molecules found in the original structure. Phases were obtained by molecular replacement using the program Phaser (McCoy et al., 2007). For the NP-exo complexed with $\mathrm{Ca}^{2+}$ structure, we used the above NP-exo structure (PDB 5LRP) as the search model for molecular replacement using Phaser.

Both models were built using coot (Emsley \& Cowtan, 2004) and refinement was carried out with PHENIX (Adams et al., 2011). The structures were validated using MOLPROBITY (Chen et al., 2010) and PROCHECK (Laskowski et al., 1993), and structural refinements statistics are listed on the Table 1. 
Structural analysis and figures were done with ESPRIPT (Gouet et al., 2003), UCSF chimera (Pettersen et al., 2004), electrostatics were calculated with APBS (Baker et al., 2001).

\section{Results and discussion}

\section{1. $\mathrm{Ca}^{2+}$ ion is acting as a strong inhibitor of the NP-exo.}

Divalent cations are known to be essential for exonuclease activity (Cisneros et al., 2009), and recent publications on Arenaviridae exonuclease have shown that its activity was $\mathrm{Mg}^{2+}$ but not $\mathrm{Ca}^{2+}$ dependent. For that reason, we assessed the effects of the 2 divalent cations $\left(\mathrm{Mg}^{2+}\right.$ and $\left.\mathrm{Ca}^{2+}\right)$ on NP-exo activity in degrading a short dsRNA H4 substrate. As expected, NP-exo exhibit a catalytic activity in the presence of $\mathrm{Mg}^{2+}$ but not in the presence of $\mathrm{Ca}^{2+}$ (Fig. 1a).

To demonstrate the effect of divalent metal binding on the thermal stability of NP-exo, we measured the change in melting temperature (Tm) by a Thermal Shift Assay (TSA) in the presence of $5 \mathrm{mM}$ of each metal ion (Fig. 1b). NP-exo without metal ions has a Tm of $49.4 \pm$ $0.5^{\circ} \mathrm{C}$. In the presence of $\mathrm{Mg}^{2+}$, the $\mathrm{Tm}$ increases by almost $5^{\circ}\left(54.3 \pm 0.5{ }^{\circ} \mathrm{C}\right)$ while an increase of $7.6^{\circ} \mathrm{C}\left(57 \pm 0.5^{\circ} \mathrm{C}\right)$ occurs in the presence of $\mathrm{Ca}^{2+}$. We can conclude that both divalent ions have a stabilizing effect on the protein, but it is worth noting that $\mathrm{Ca}^{2+}$ which inhibits the 3 '-5' exonuclease activity is also a better stabilizer than $\mathrm{Mg}^{2+}$. Taking into account these observations, we undertook a crystallographic study in order to understand the relation between the observed Tm differences and the possible structural modifications induced by the above metal atoms.

\subsection{Structure of the Mopeia virus 3'-5' exonuclease in complex with divalent ions.}

Two different structures of the NP-exo complexed either with $\mathrm{Ca}^{2+}$ or $\mathrm{Mg}^{2+}$ were solved from crystals belonging to different space groups. The structure complexed with $\mathrm{Mg}^{2+}$ was solved in the space group P121 containing two molecules within a unit cell of a volume $=$ 237,626.4 $\AA^{3}$ (Fig. 2a). The second structure, complexed with $\mathrm{Ca}^{2+}$ was solved in the space group C121 containing one molecule within a unit cell of a volume $=237,689.6 \AA^{3}$ (Fig. 2b). Complete parameters of the respective unit cells are reported in Table 1. It is worth noting that both crystal forms were obtained from the same reservoir screening condition. $\mathrm{Ca}^{2+}$ was introduced during the gel filtration; replacing $\mathrm{MgCl}_{2}$ in the gel filtration buffer without altering the gel filtration profile (Fig. 1c). Both structures were determined by molecular replacement using Phaser. The P121 structure has been refined to $1.94 \AA$ resolution with Rwork $19.62 \%$ and R-free $24.5 \%$ whereas the $\mathrm{C} 121$ structure was refined to $1.47 \AA$ resolution with R-work $17.04 \%$ and R-free $19.76 \%$ (Table 1). 
Concerning the exact nature of the ion, let's recall that from the purification method we have complexed a catalytic ion free enzyme with either $\mathrm{Mg}^{2+}$ or $\mathrm{Ca}^{2+}$ through a specific gel filtration buffer. In addition, the identity of the ion determined for each structure is confirmed from coordination geometry, distances as well as B-factor and occupation refinement statistics.

Both structures revealed that NP-exo consist of $2 \beta$-sheets (with 6 mixed strands and 2 anti-parallel strands) and $8 \alpha$-helices connected by a series of loops. These secondary structure elements are arranged to form the central $\beta$-sheet sandwiched by $3 \alpha$-helices on one side and $7 \alpha$-helices on the opposite side (Fig. 3). Two flexible regions are clearly defined within the structure; the 'basic loop' region (residues 514-526) near the active site and the Cterminal arm (residues 549-570) that extends away from the protein core (Fig 3b).

The overall r.m.s.d between both structures is $\sim 0.8 \AA$ (Table 2), which allows us to observe that the ion swapping does not affect the overall structure.

In each structure, we noticed the presence of two divalent ions : 1) A structural $\mathrm{Zn}^{2+}$ metal is present near the active site and coordinated by a classical zinc binding site composed of residues : E 400, C 507, H 510 and C 530 (highly conserved throughout the Arenaviridae). 2) A second metal ion is present on the active site modelled as $\mathrm{Mg}^{2+}$ or $\mathrm{Ca}^{2+}$ in the respective NP-exo structures (Fig. 4).

The coordination of $\mathrm{Mg}^{2+}$ and $\mathrm{Ca}^{2+}$ ions at the active site are represented in (Fig. 5). $\mathrm{Mg}^{2+}$ is observed with a coordination number of 4 for which three catalytic residues D390, E392, D534 and one $\mathrm{H}_{2} \mathrm{O}$ molecule directly interacts with the ion ; whereas for $\mathrm{Ca}^{2+}$ the coordination observed is 6 , involving the same catalytic residues and three water molecules. These coordination numbers fall into the described metal-ligand geometry (Harding, 2001, 2000) and are frequently observed in protein structures in the PDB that fall in the same resolution ranges (Zheng et al., 2008).

Also, the corresponding distances between the ion and the coordinating amino acids (Fig. $5 b)$ are in accordance to the typical distances observed for $\mathrm{Mg}^{2+}(\sim 2.07 \AA)$ and $\mathrm{Ca}^{2+}(\sim 2.42 \AA)$ respectively (Harding, 1999).

Finally, the analysis of B-factors of both structure allows us to observe a relatively low B-factor for each ion, indicative of a proper refinement of the assigned ion (Fig. 6a). Indeed, in the case of NP-exo complexed with $\mathrm{Mg}^{2+}$, the B-factor of the $\mathrm{Mg}^{2+}$ atom is $36 \AA^{2}$ while the average B-factor of the structure is $37 \AA^{2}$. In the case of NP-exo complexed with $\mathrm{Ca}$, the B-factor of the $\mathrm{Ca}^{2+}$ atom is $15 \AA^{2}$ while the average $\mathrm{B}$ factor of the structure is $19 \AA^{2}$. 


\subsection{Ion swaping induces crystal polymorphism.}

As discussed above the main crystallographic effect of the ion swapping is the change of the crystallization space group. Indeed, the replacement of $\mathrm{Mg}^{2+}$ with $\mathrm{Ca}^{2+}$ does not affect the overall structure but induces a change in the surface charge distribution around both structural $\left(\mathrm{Zn}^{2+}\right)$ and catalytic $\left(\mathrm{Mg}^{2+}\right)$ binding sites (Fig. 6b).

This effect seems to be sufficient to alter relative positions between adjacent molecules within the crystal (Fig. 2 and 3a), and it thus changes the crystallization space group. In an interesting study of residue mutagenesis coupled with metal ions swapping, Laganowsky (Laganowsky et al., 2011) demonstrated the possibility to influence crystal packing as well as crystallization space group for a given protein. In their study, the metallic ion localized at selected mutated residues at the protein interface triggers drastic crystal packing changes driven by metal coordination properties. In our study, we observed the transition of the space group for the same protein and crystallization condition after an ion swapping experiment, which does not involve ions at the protein interface but at the heart of the catalytic site. The main effect of metal ion swapping in our case concerns only the electrostatic surface of the protein around the active site (Fig 6b), and we propose that such an effect is sufficient to induce crystal polymorphism.

This observation is of great interest to further characterize the mode of polymerization of NP. Indeed, NP primary function is to package genomic RNA; considering that NP-RNA EM analysis does not show domains decorating the polymer of NP-RNA, it is reasonable to propose that the exonuclease domain is also contributing in part to the polymer assembly. The use of calcium could therefore trigger a partial electrostatic modification that could lead to an improper self-positioning of the exonuclease domain in respect to the polymer formation. Such an effect could be used in kinetic studies of the polymer formation to determine the actual contribution of the exonuclease domain.

\subsection{Structural basis for inhibition of $3^{\prime}-5$ ' exonuclease activity of NP-exo by $\mathrm{Ca}^{2+}$ ions}

To further investigate the findings on $\mathrm{Ca}^{2+}$ inhibition of the $3^{\prime}-5^{\prime}$ exonuclease activity, we structurally compared the active sites of the NP-exo complexed $\mathrm{Mg}^{2+}$ to that of the NP-exo complex with $\mathrm{Ca}^{2+}$, and other known Arenavirus exonuclease domains (Fig. 7 and Table 2).

The analysis of the structure of NP-exo MOPV, confirms that the two major features such as the fold and the presence of two ion binding sites (catalytic and structural) are conserved within the Arenaviridae (Qi et al., 2010; Brunotte et al., 2011; Hastie et al., 2012; West et al., 2014; Jiang et al., 2013; Hastie et al., 2011) (Fig. 7). Structural alignment tells us that the 
only major difference between the different structures are located in the 'basic loop' region located above the active site (Fig. 3 and 7). In all cases the superimposition of the structure shows a conserved active site between all the different structures (Fig.7a).

The larger atomic radius of $\mathrm{Ca}^{2+}$, the higher coordination number, the increase of the coordination distances and the surface electrostatic modifications make the protein unable to carry out phosphoryl transfer reactions (Fig. 1a). Therefore, a possible explanation is that when $\mathrm{Ca}^{2+}$ replaces $\mathrm{Mg}^{2+}$, its higher degree of possible coordination geometry and ligand number makes it unable to destabilize the enzyme-RNA complex and ease product formation. We speculate, the presence of $\mathrm{Ca}^{2+}$ in the active site results in an increased energy barrier for the reaction, thus inhibiting the reaction.

From our functional and structural analysis, we conclude that the NP-exo MOPV structure is compatible with the general mechanism for RNA hydrolysis which includes a two metal mechanism described by (Steitz \& Steitz, 1993) and (Jiang et al., 2013). Therefore any structural restraint on residues D390, E392, D534 of NP-exo MOPV, which are directly coordinating the catalytic ion, lead to partial or complete lost of catalytic activity as shown in the $\mathrm{Ca}^{2+}$ containing structure and biochemical experiment.

\section{Conclusion}

We report the crystallographic structures of the NP-exo MOPV complexed with two divalent ions $\left(\mathrm{Mg}^{2+}\right.$ and $\left.\mathrm{Ca}^{2+}\right)$, together with the first experimental biochemical assay of Mopeia virus exonuclease and its inactivation in the presence of Calcium. Our data present clear evidence that calcium exchange not only inhibits the catalytic reaction but can induce modification of the surface electrostatic. That modification is strong enough to modify the relative position of two neighbouring domains triggering crystal polymorphism. The consequences are of great interest to further study apo enzyme structures complexed with its natural substrate without risking degradation of the latter, as well influencing the NP mode of polymerisation.

Figure 1 Divalent cation-depended exonuclease activity and thermal stability of NP-exo MOPV. (a) Effect of calcium ion on exonuclease activity of NP-exo. Equal amounts of wild type protein (WT) or D390A mutant were incubated with dsRNA for 0, 5, 30 and 60 mins in the presence of $5 \mathrm{mM} \mathrm{Mg}^{2+}$ or 
$\mathrm{Ca}^{2+}$. Neg Ctrl indicates the substrate without proteins. Digestion products were separated on a $20 \%$ denaturing PAGE and revealed by autoradiography. (b) Thermal shift assay for NP-exo MOPV preformed on the protein alone (blue) or in the presence of $\mathrm{Mg}^{2+}$ (red) or $\mathrm{Ca}^{2+}$ (yellow). (c) Gel filtration profile of NP-exo MOPV using purification buffer with $\mathrm{Ca}^{2+}$ (blue) or $\mathrm{Mg}^{2+}$ (red).

Figure 2 The unit cell of the active featuring $\mathrm{Mg}^{2+}$ ion (a) and inactive featuring $\mathrm{Ca}^{2+}$ ion (b) of NPexo MOPV, oriented along the $\mathrm{a}, \mathrm{c}$ and $\mathrm{b}$ crystallographic directions from right to left respectively. The asymmetric units fulfilling the unit cell of $\mathrm{Mg}^{2+}$ and $\mathrm{Ca}^{2+}$ are depicted by colors cyan and green respectively.

Figure 3 Structure of NP-exo MOPV. (a) Sequence of NP-exo with secondary structure elements indicated above. Red stars $\left(^{*}\right)$ and arobase (@) depict amino acid residues that make contacts with $\mathrm{Zn}^{2+}$ and $\mathrm{Mg}^{2+}\left(\mathrm{or}^{2+}{ }^{2+}\right)$ ions respectively. Bold B corresponds to residues involved in non-crystallographic interfaces of the magnesium structure while Italic A correspond to residues involved in the crystallographic interface the Calcium structure. Red letters indicate distances $<3,2 \AA$ and black letters distances in the range of 3,2-4 $\AA$. (b) Ribbon representation of NP-exo MOPV from front (left), side (center) and the top (right). Helices are colored orange, $\beta$-strands in green and loops in cyan. The light green sphere corresponds to $\mathrm{Mg}^{2+}$ ion and the purple sphere represents the $\mathrm{Zn}^{2+}$ ion.

Figure 4 2Fo-Fc OMIT maps for the metal ion binding site of NP-exo MOPV contoured at 1.3б. (a) Showing map around $\mathrm{Mg}^{2+}$. (b) Showing map around $\mathrm{Ca}^{2+}$.

Figure 5 Active site of NP-exo MOPV-Mg complex compared to NP-exo MOPV-Ca complex. (a) Cartoon representation of NP-exo MOPV active showing $\mathrm{Mg}^{2+}$ ion (green sphere) coordination geometry compared to $\mathrm{Ca}^{2+}$ ion (grey sphere) coordination. Metal ion coordination is denoted with dotted lines. (b) Ligplot representation showing the coordination distances in $\AA$ of $\mathrm{Mg}^{2+}$ ion compared to $\mathrm{Ca}^{2+}$ ions.

Figure 6 Changes in B-factor and surface electrostatic induced by metal ion swapping. (a) A display of the B-factors of NP-exo MOPV-Mg and NP-exo MOPV-Ca using ribbon thickness. Ribbon thickness denotes the average B-factor of each structure. On the corresponding color key, regions with high B-factors are coloured purple and regions with lowest B-factors cyan. (b) Surface electrostatic potential calculated by APBS from -10 (red) to +10 (blue) kT/e. The ion swapping affects mainly the active site (Top) as well as the $\mathrm{Zn}$ finger site (middle) while it leaves unaffected the rest of the surface (bottom). The slight modification of the potential is in the origin of the different crystal arrangements shown in Figure 2.

Figure 7 Structural comparison of NP-exo MOPV with LASV, LCMV and TACV exonuclease domains. (a) Structure based alignment of the C-terminal domain of the NPs of the mentioned arenaviruses. Highly conserved residues are shaded in red. Secondary structure elements corresponding to each crystal structure are displayed above the sequence alignment. They are coloured as follows, MOPV (orange), LASV (cyan), LCMV (pink) and TCRV (green). (b) Superposition of NP-exo MOPV with LASV(PDB code:3Q7C), LCMV (PDB code : 4Q6I) or TCRV (PDB code:4GVE). The r.m.s.d. of the superposition is reported in Table 2. 
Table 1 Data-collection and refinement statistics for exonuclease domain of NP Mopeia complexed with Magnesium and Calcium.

\begin{tabular}{|c|c|c|}
\hline Crystal & NP-exo MOPV-Mg & NP-exo MOPV-Ca \\
\hline Instrument & ESRF - ID30A & ESRF - ID23 \\
\hline Wavelength $(\AA)$ & 0.9677 & 0.8729 \\
\hline Space group & P 121 & C 121 \\
\hline Unit cell parameters a, b, c $(\AA)$ & $45.44,38.18,137.09$ & $131.96,37.91,48.99$ \\
\hline$\alpha, \beta, \gamma\left(^{\circ}\right)$ & $90,91.99,90$ & $90,104.07,90$ \\
\hline Resolution range $(\AA \AA)$ & $45.41-1.94(2.01-1.94)$ & $47.52-1.47(1.52-1.47)$ \\
\hline Total reflections & $70497(6945)$ & $226068(20337)$ \\
\hline Unique reflections & $35271(3480)$ & 40307 (3926) \\
\hline Completeness (\%) & $99.71(98.28)$ & $99.74(97.66)$ \\
\hline Mean I/sigma(I) & $14.88(5.11)$ & $14.28(2.80)$ \\
\hline R-merge & $0.033(0.17)$ & $0.073(0.50)$ \\
\hline R-meas & 0.047 & 0.081 \\
\hline Multiplicity & $2.0(2.0)$ & $5.6(5.2)$ \\
\hline \multicolumn{3}{|l|}{ Refinement } \\
\hline R-work & $0.196(0.240)$ & $0.170(0.253)$ \\
\hline R-free & $0.245(0.300)$ & $0.198(0.270)$ \\
\hline \multicolumn{3}{|l|}{ No. of atoms } \\
\hline Protein residues & 412 & 206 \\
\hline Water & 289 & 328 \\
\hline Ligands & 4 & 9 \\
\hline \multicolumn{3}{|l|}{ B-Factors $(\hat{A})^{2}$} \\
\hline Wilson B-factor & 28.35 & 12.26 \\
\hline Average B-factor & 37.10 & 18.30 \\
\hline Macromolecules & 36.90 & 16.50 \\
\hline Ligands & 31.10 & 25.40 \\
\hline Solvent $(\%)$ & 40.30 & 27.10 \\
\hline \multicolumn{3}{|l|}{ R.m.s deviations } \\
\hline RMS lengths $(\AA)$ & 0.008 & 0.009 \\
\hline RMS angles $\left(^{\circ}\right)$ & 1.18 & 1.26 \\
\hline \multicolumn{3}{|l|}{ Ramachandran plot } \\
\hline Ramachandran favored (\%) & 98 & 98 \\
\hline Ramachandran allowed (\%) & 2 & 2 \\
\hline PDB code & $5 \mathrm{LRP}$ & $5 \mathrm{LS} 4$ \\
\hline
\end{tabular}


Table 2 Sequences and structures conservation of Arenaviridae exonuclease

\begin{tabular}{ccccc}
\hline Virus & PDB code & Observed ions & $\begin{array}{c}\text { Sequence } \\
\text { identity (\%) }\end{array}$ & $\begin{array}{c}\text { Overall } \\
\text { r.m.s.d (A) }\end{array}$ \\
\hline Mopeia virus & 5LRP & $\mathrm{Mg} / \mathrm{Zn}$ & - & - \\
Lassa virus & 3LS4 & $\mathrm{Ca} / \mathrm{Zn}$ & 100 & 0.45 \\
LCM virus & $4 \mathrm{O} 6 \mathrm{M}$ & $\mathrm{Mn} / \mathrm{Zn}$ & 56.79 & 0.72 \\
Tacaribe virus & $4 \mathrm{GVE}$ & $\mathrm{Mg} / \mathrm{Zn}$ & 55.79 & 0.78 \\
\hline
\end{tabular}

Acknowledgements - This work was supported by ANR grant ArenaBunya-L (ANR-11-BSV80019), the Fondation Infection Méditerranée, the SILVER Large Scale Collaborative Project (grant agreement $\mathrm{n}^{\circ}$ 260644) of the European Union 7th Framework and the French Infrastructure for Integrated Structural Biology (FRISBI) ANR-10-INSB-05-01. The authors also thank ESRF for provision of synchrotron beam time at ID30, and ID23 beamlines and their staff for support during data collection. Authors thanks Dr. S. Baize from Institut Pasteur providing NP Mopeia virus gene, and Dr. R. JONES for proofreading the manuscript.

\section{References}

Adams, P. D., Afonine, P. V, Bunkóczi, G., Chen, V. B., Echols, N., Headd, J. J., Hung, L.-W., Jain, S., Kapral, G. J., Grosse Kunstleve, R. W., McCoy, A. J., Moriarty, N. W., Oeffner, R. D., Read, R. J., Richardson, D. C., Richardson, J. S., Terwilliger, T. C. \& Zwart, P. H. (2011). Methods. 55, 94-106.

Baker, N. A., Sept, D., Joseph, S., Holst, M. J. \& McCammon, J. A. (2001). Proc. Natl. Acad. Sci. U. S. A. 98, 10037-10041.

Beaugé, L. \& Campos, M. A. (1983). Biochim. Biophys. Acta. 729, 137-149.

Bouvet, M., Debarnot, C., Imbert, I., Selisko, B., Snijder, E. J., Canard, B. \& Decroly, E. (2010). PLoS Pathog. 6, 13.

Brunotte, L., Kerber, R., Shang, W., Hauer, F., Hass, M., Gabriel, M., Lelke, M., Busch, C., Stark, H., Svergun, D. I., Betzel, C., Perbandt, M. \& Günther, S. (2011). J. Biol. Chem. 286, 38748-38756. 
Chen, V. B., Arendall, W. B., Headd, J. J., Keedy, D. A., Immormino, R. M., Kapral, G. J., Murray, L. W., Richardson, J. S. \& Richardson, D. C. (2010). Acta Crystallogr. Sect. D Biol. Crystallogr. 66, 12-21.

Cisneros, G. A., Perera, L., Schaaper, R. M., Pedersen, L. C., London, R. E., Pedersen, L. G. \& Darden, T. A. (2009). J. Am. Chem. Soc. 131, 1550-1556.

Colvin, R. A., Oibo, J. A. \& Allen, R. A. (1991). Cell Calcium. 12, $19-27$.

Emsley, P. \& Cowtan, K. (2004). Acta Crystallogr. D. Biol. Crystallogr. 60, 2126-2132.

Fukushima, Y. \& Post, R. L. (1978). J. Biol. Chem. 253, 6853-6862.

Gouet, P., Robert, X. \& Courcelle, E. (2003). Nucleic Acids Res. 31, 3320-3323.

Harding, M. M. (1999). Acta Crystallogr. D. Biol. Crystallogr. 55, 1432-1443.

Harding, M. M. (2000). Acta Crystallogr. Sect. D Biol. Crystallogr. 56, 857-867.

Harding, M. M. (2001). Acta Crystallogr. D. Biol. Crystallogr. 57, 401-411.

Hastie, K. M., Kimberlin, C. R., Zandonatti, M. A., MacRae, I. J. \& Saphire, E. O. (2011). Proc. Natl. Acad. Sci. U. S. A. 108, 2396-2401.

Hastie, K. M., King, L. B., Zandonatti, M. A. \& Saphire, E. O. (2012). PLoS One. 7, e44211.

Irimia, A., Zang, H., Loukachevitch, L. V., Eoff, R. L., Guengerich, F. P. \& Egli, M. (2006). Biochemistry. 45, 5949-5956.

Jiang, X., Huang, Q., Wang, W., Dong, H., Ly, H., Liang, Y. \& Dong, C. (2013). J. Biol. Chem. 288, 16949-16959.

Junop, M. S. \& Haniford, D. B. (1996). EMBO J. 15, 2547-2555.

Kabsch, W. (2010). Acta Crystallogr. D. Biol. Crystallogr. 66, 125-132.

Knauf, P. a, Proverbio, F. \& Hoffman, J. F. (1974). J. Gen. Physiol. 63, 324-336.

Laganowsky, A., Zhao, M., Soriaga, A. B., Sawaya, M. R., Cascio, D. \& Yeates, T. O. (2011). Protein Sci. 20, 1876-1890.

Laskowski, R. A., MacArthur, M. W., Moss, D. S. \& Thornton, J. M. (1993). J. Appl. Crystallogr. 26, 283-291.

Lu, S.-Y., Huang, Z.-M., Huang, W.-K., Liu, X.-Y., Chen, Y.-Y., Shi, T. \& Zhang, J. (2013). Proteins. 81, 740-753.

McCoy, A. J., Grosse-Kunstleve, R. W., Adams, P. D., Winn, M. D., Storoni, L. C. \& Read, R. J. (2007). J. Appl. Crystallogr. 40, 658-674.

Palermo, G., Cavalli, A., Klein, M. L., Alfonso-Prieto, M., Dal Peraro, M. \& De Vivo, M. (2015). Acc. Chem. Res. 48, 220-228.

Peeraer, Y., Rabijns, A., Collet, J. F., Van Schaftingen, E. \& De Ranter, C. (2004). Eur. J. Biochem. 271, 3421-3427.

Pettersen, E. F., Goddard, T. D., Huang, C. C., Couch, G. S., Greenblatt, D. M., Meng, E. C. \& Ferrin, T. E. (2004). J. Comput. Chem. 25, 1605-1612.

Pingoud, V., Wende, W., Friedhoff, P., Reuter, M., Alves, J., Jeltsch, A., Mones, L., Fuxreiter, M. \& Pingoud, A. (2009). J. Mol. Biol. 393, 140-160. 
Qi, X., Lan, S., Wang, W., Schelde, L. M., Dong, H., Wallat, G. D., Ly, H., Liang, Y. \& Dong, C. (2010). Nature. 468, 779-783.

Rosta, E., Yang, W. \& Hummer, G. (2014). J. Am. Chem. Soc. 136, 3137-3144.

SKOU, J. C. (1957). Biochim. Biophys. Acta. 23, 394-401.

Steitz, T. a \& Steitz, J. a (1993). Proc. Natl. Acad. Sci. U. S. A. 90, 6498-6502.

Vipond, I. B., Baldwin, G. S. \& Halford, S. E. (1995). Biochemistry. 34, 697-704.

West, B. R., Hastie, K. M. \& Saphire, E. O. (2014). Acta Crystallogr. Sect. D Biol. Crystallogr. 70, 1764-1769.

Zheng, H., Chruszcz, M., Lasota, P., Lebioda, L. \& Minor, W. (2008). J. Inorg. Biochem. 102, 17651776. 


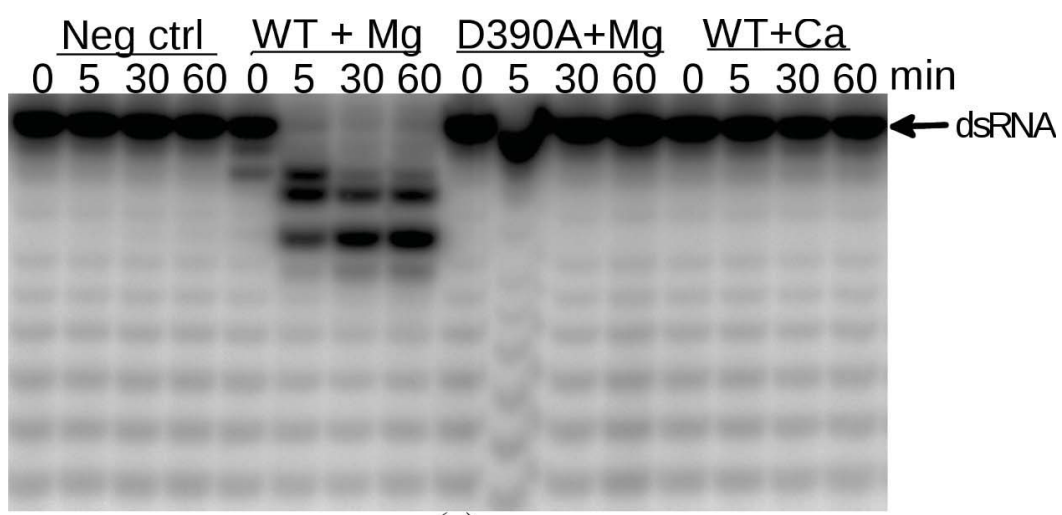

(a)
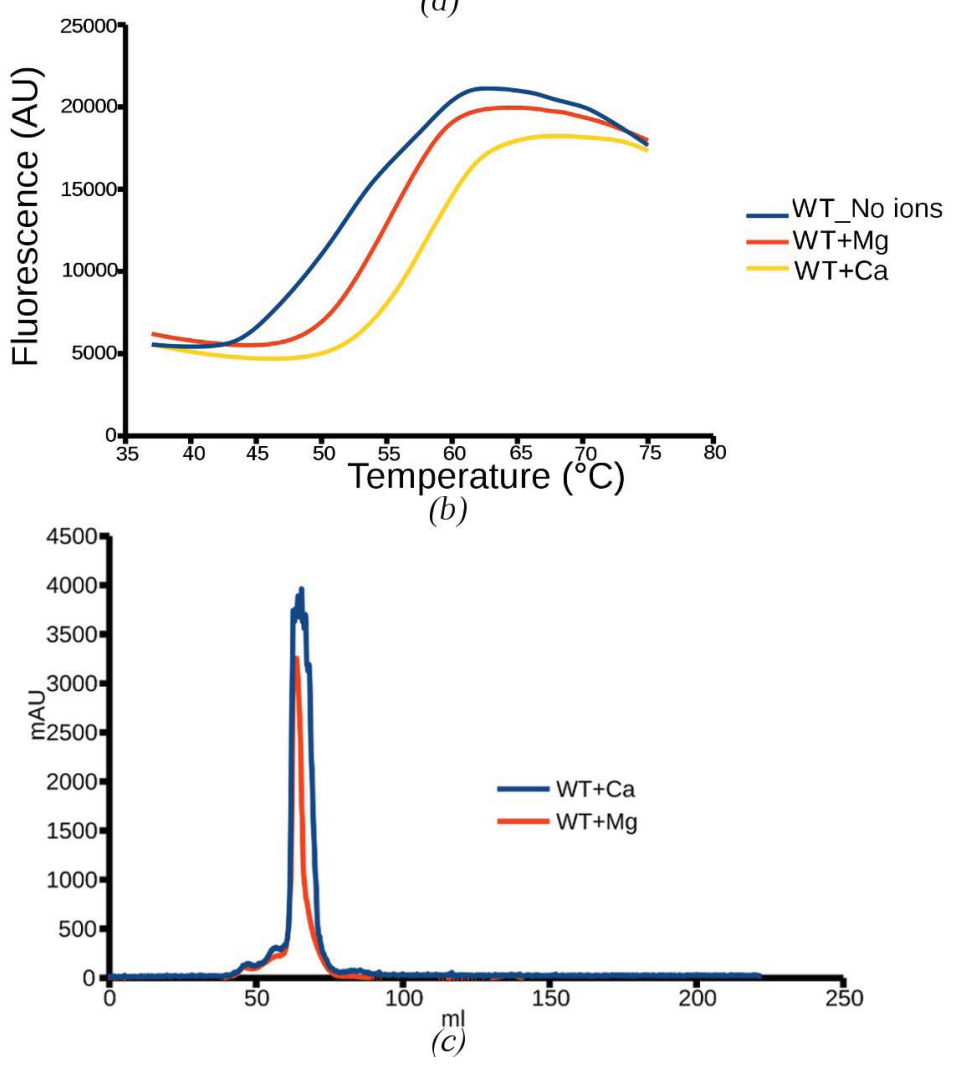

Figure 1 

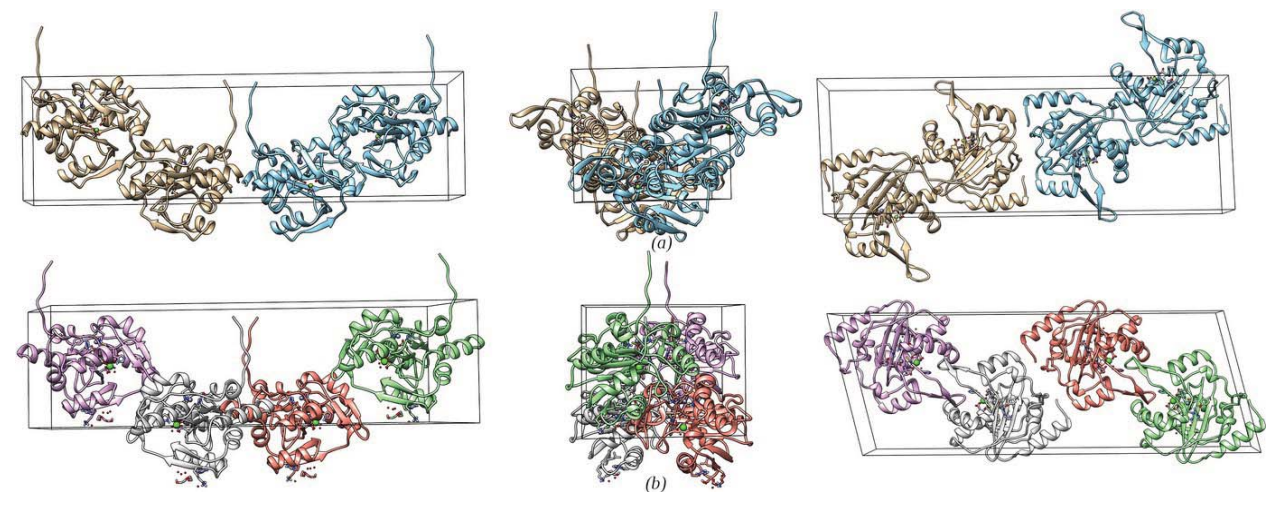

Figure 2 


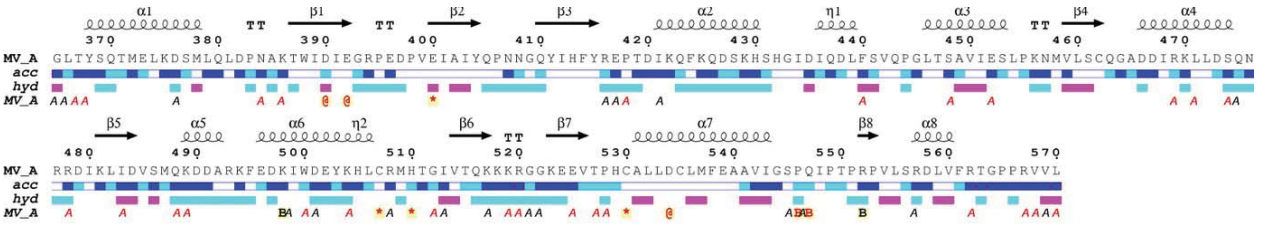

(a)
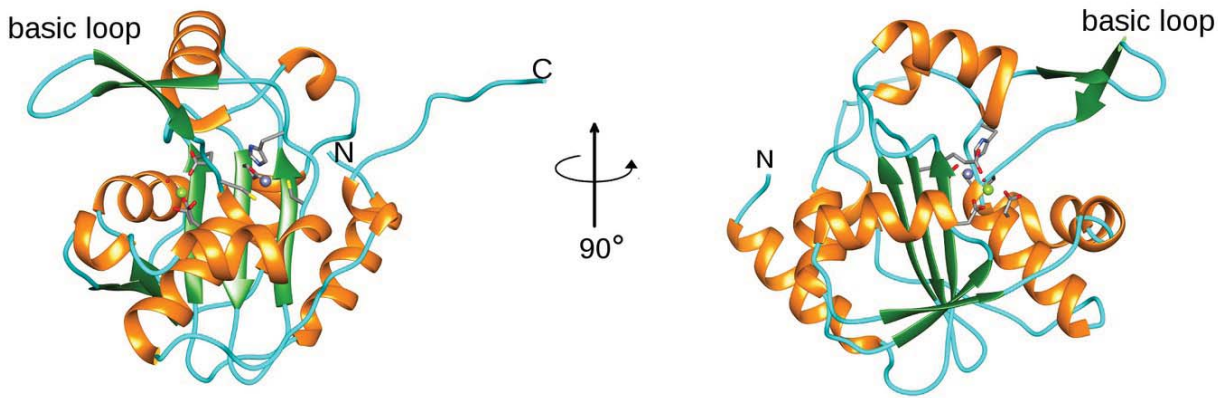

(b)

Figure 3 


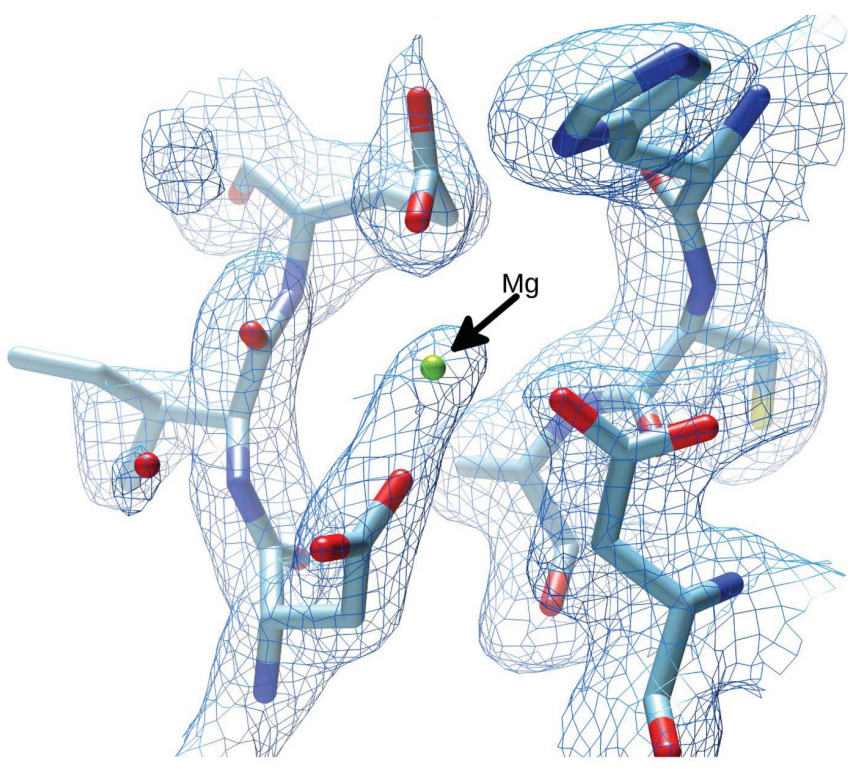

(a)

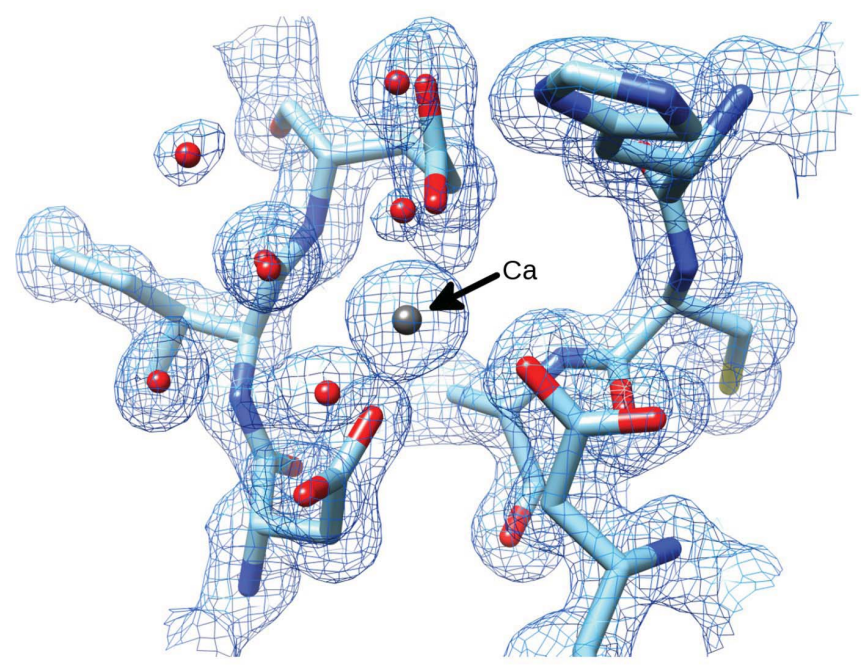

(b)

Figure 4 

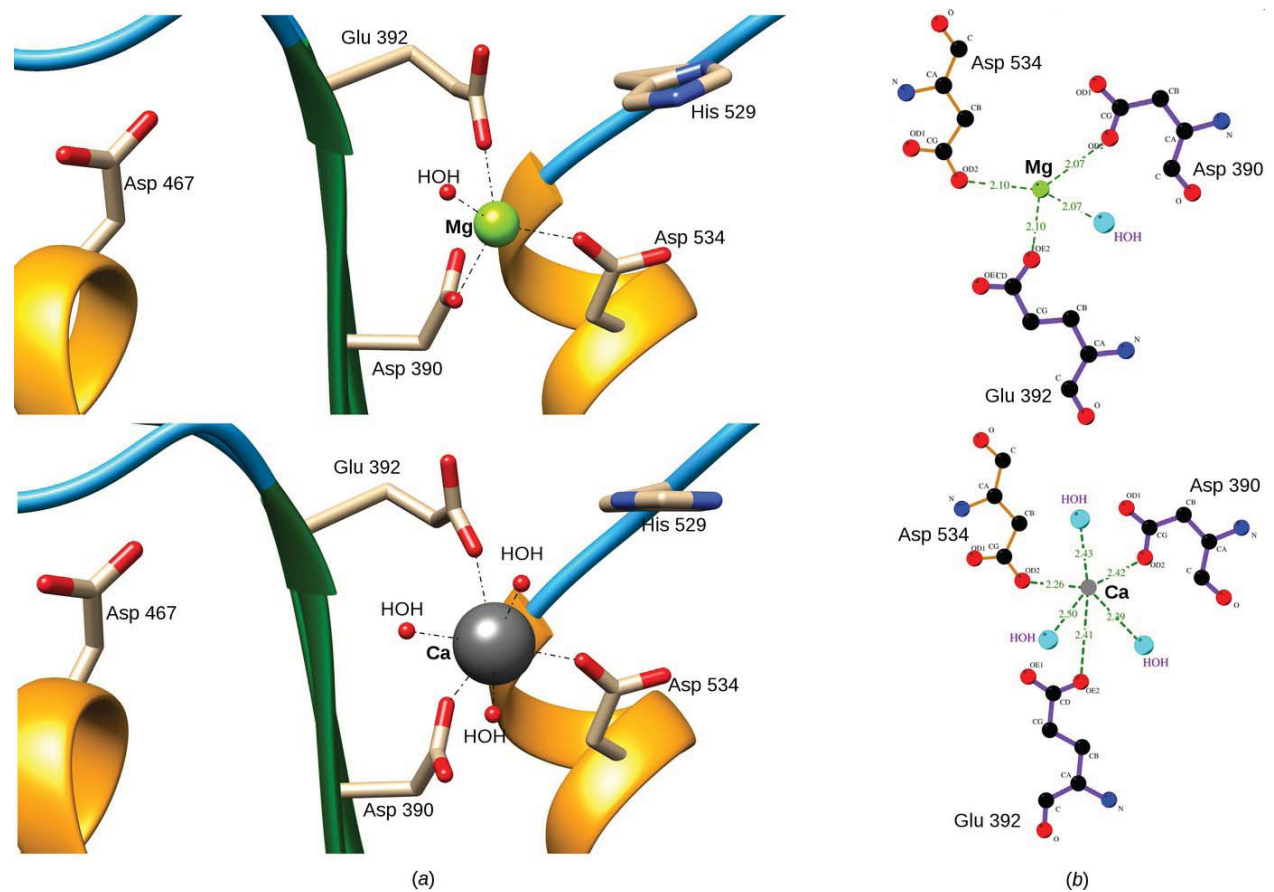

(b)

Figure 5 

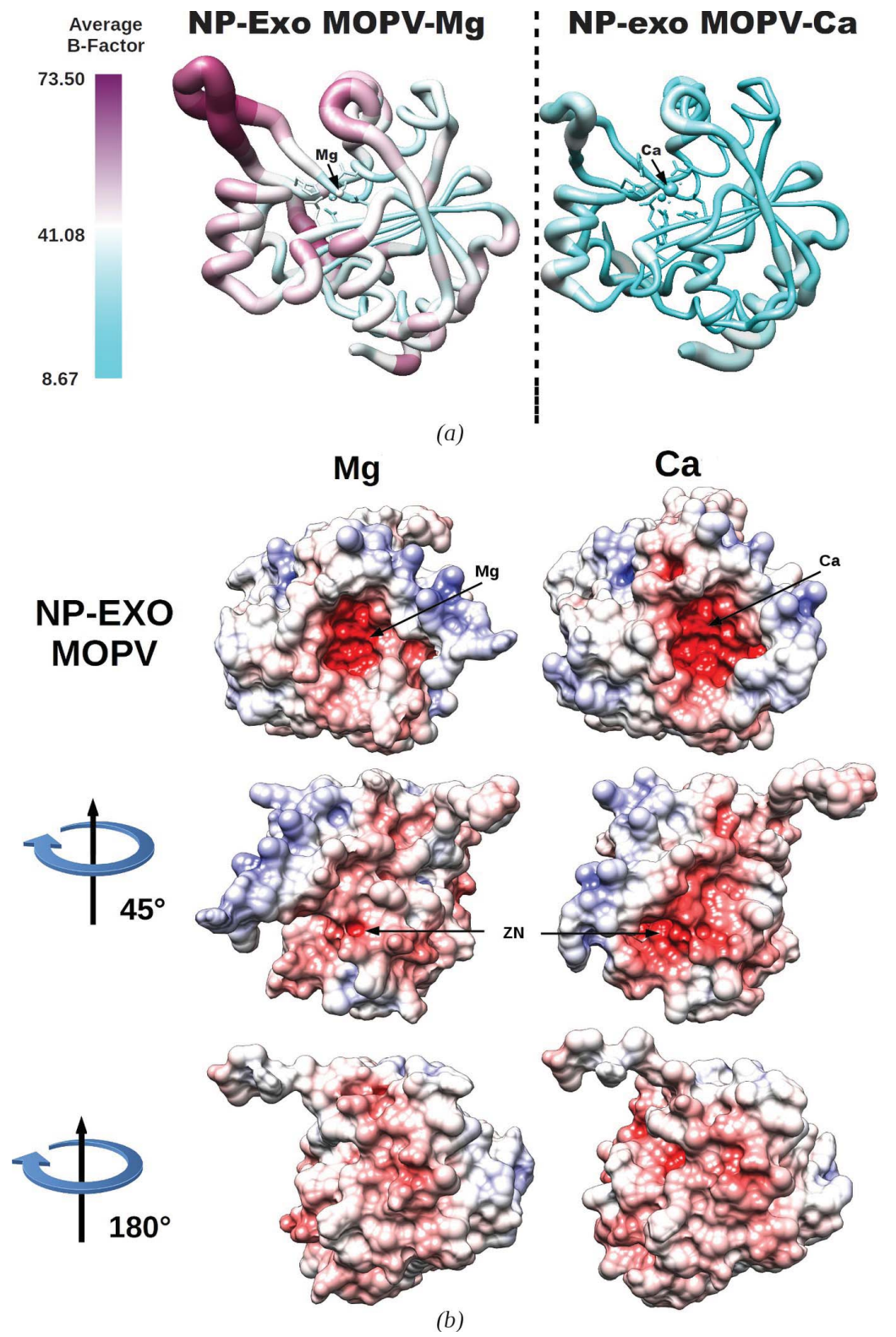

Figure 6 

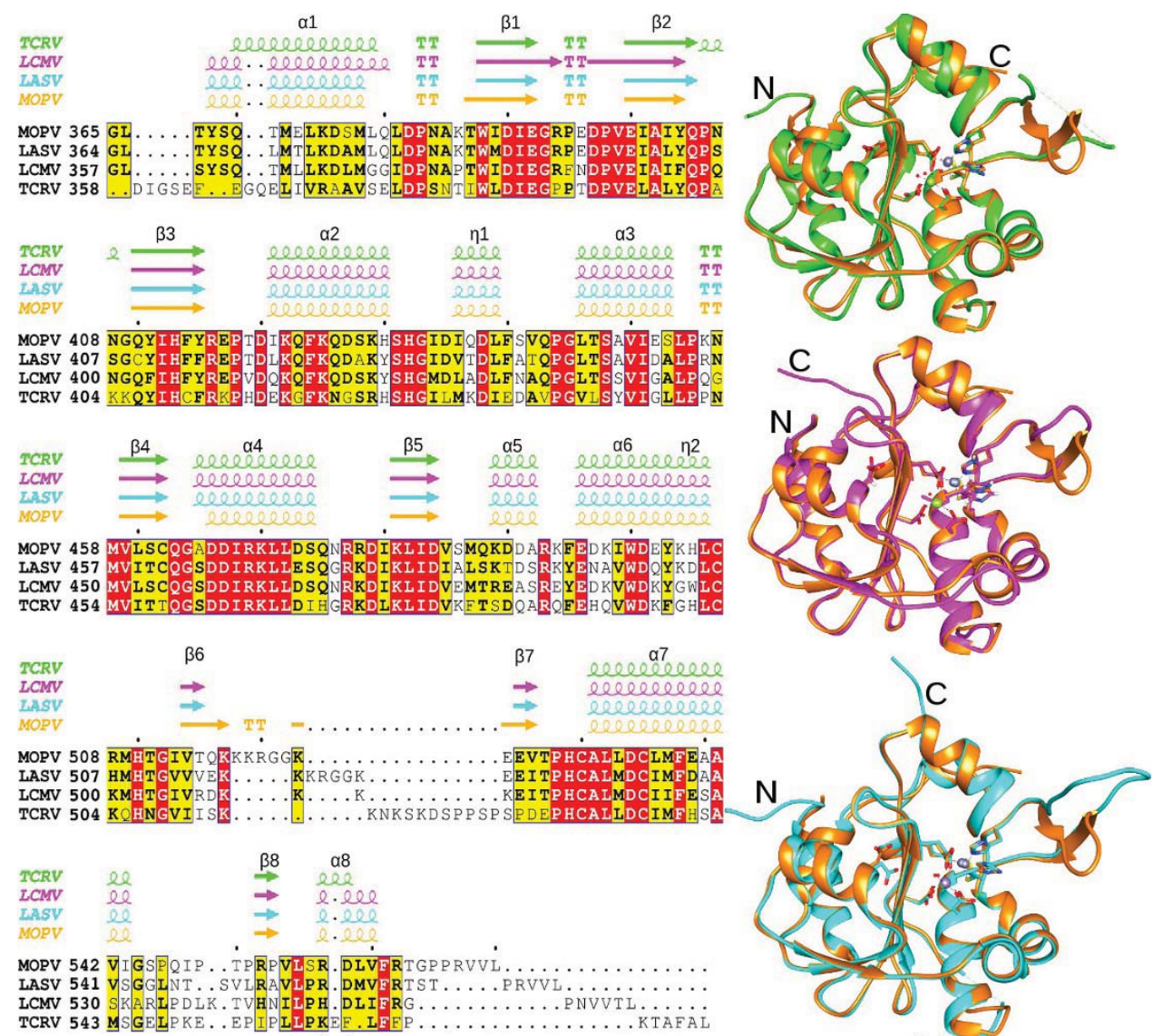

(b)

Figure 7 